\title{
Choosing an Effective and Safe Direct Aspiration Setup for Tortuous Anatomy in Acute Ischemic Stroke: In vitro Study in a Physiological Flow Model
}

\author{
Auswahl einer effektiven und sicheren Kontaktaspirationstechnik \\ beim akuten ischämischen Schlaganfall in schwieriger \\ Gefäßanatomie: In-vitro-Studie in einem physiologischen \\ Flussmodell
}

Authors

Jawid Madjidyar, Lars Nerkada, Naomi Larsen@, Fritz Wodarg, Johannes Hensler@, Olav Jansen

Affiliation

Department of Radiology and Neuroradiology, University

Hospital Schleswig-Holstein, Kiel, Germany

Key words

ischemia/infarction, thrombolysis, angiography, brain

received 29.05 .2020

accepted 29.09.2020

published online 19.11.2020

Bibliography

Fortschr Röntgenstr 2021; 193: 544-550

DOI 10.1055/a-1288-1475

ISSN 1438-9029

(C) 2020. Thieme. All rights reserved.

Georg Thieme Verlag KG, Rüdigerstraße 14,

70469 Stuttgart, Germany

Correspondence

Jawid Madjidyar

Department of Radiology and Neuroradiology, University

Hospital Schleswig-Holstein, Arnold-Heller-Str. 3, 24105 Kiel, Germany

Tel.: $+49 / 431 / 5974806$

Fax: $+49 / 431 / 5974913$

jawid.madjidyar@uksh.de

\section{ZUSAMMENFASSUNG}

Ziel Die direkte Kontaktaspiration (ADAPT) ist eine effektive Thrombektomieoption bei Patienten mit akutem ischämischem Schlaganfall. Ballon-Führungskatheter (BGC) scheinen die Effektivität von Stent-Retrievern und ADAPT zu verbessern. Die letzte Generation der 6F-Aspirationskatheter passt nur durch 9F-BGC. Diese sind rigide und in elongierter Anatomie schwierig zu positionieren. In dieser experimentellen Studie wurde die Effektivität von 6F-ADAPT ohne BGC mit der von 5F-ADAPT mit einem flexiblen 8F-BGC verglichen.

Material und Methoden Ein fibrinreicher (weißer) oder ein Erythrozyten-reicher (roter) Thrombus wurde in das M1-Seg- ment eines transparenten Silikonphantoms mit physiologischer Architektur platziert. Physiologische hämodynamische Bedingungen sind eingestellt worden. Die Thrombektomie wurde mit einem 6F-Aspirationskatheter über eine lange $8 \mathrm{~F}$-Schleuse oder mit einem 5F-Aspirationskatheter über einen flexiblen 8F-BGC unter direkter visueller Kontrolle durchgeführt. Primäre Endpunkte waren die Anzahl von Rekanalisationsmanövern und die Anzahl distaler Embolien.

Ergebnisse Es sind 10 Experimente pro Thrombusart und Thrombektomietechnik durchgeführt worden $(n=40)$. mTICI 3 nach einem Manöver mittels 6F-ADAPT wurde zu $80 \%$ in roten Thromben und $90 \%$ in weißen Thromben erreicht; es traten distale Embolien in $10 \%$ bzw. $20 \%$ der Fälle auf. Mittels 5F-ADAPT kombiniert mit BGC wurde $\mathrm{mTICI} 3$ nach einem Manöver zu $90 \%$ in roten Thromben und $100 \%$ in weißen Thromben erreicht; es traten distale Embolien in jeweils 10\% der Fälle auf. In fast allen Experimenten (beide Techniken) verstopften die Thromben den Aspirationskatheter. Es konnten keine statistisch signifikanten Unterschiede abhängig von der Thrombuskomposition oder der Thrombektomietechnik festgestellt werden.

Diskussion 6F-ADAPT ohne BGC war genauso effektiv wie 5F-ADAPT kombiniert mit BGC, jeweils mit hohen Rekanalisationsraten nach einem Manöver und geringer Rate an distalen Embolien. Insbesondere bei schwieriger Anatomie sollten diese Techniken als Alternative zu einem rigiden 9F-BGC in Betracht gezogen werden. Die Thrombuskomposition schien nicht relevant zu sein.

\section{Kernaussagen:}

- 6F-ADAPT ohne BGC und 5F-ADAPT mit BGC waren sehr effektiv und gleichwertig.

- Beide Techniken sollten für schwierige Gefäßanatomien erwogen werden.

- Die Thrombuskomposition zeigte in diesem Aufbau keinen Effekt auf die Rekanalisationsrate. 


\section{ABSTRACT}

Purpose A direct aspiration first pass technique (ADAPT) is an effective thrombectomy option in patients with acute ischemic stroke. Balloon guide catheters (BGC) seem to improve the efficacy of stent retrievers and ADAPT. The last generation $6 \mathrm{~F}$ aspiration catheters require $9 \mathrm{~F} \mathrm{BGCs,} \mathrm{which} \mathrm{are} \mathrm{ri-}$ gid devices that are challenging to position in a tortuous anatomy. In this experimental study the efficacy of 6F ADAPT alone and 5F ADAPT combined with 8F BGC was evaluated.

Materials and Methods Either a fibrin rich (white) clot or an RBC rich (red) clot was placed in the M1 segment of a transparent silicon phantom. Physiological hemodynamic conditions were maintained. The clots were retrieved by $6 \mathrm{~F}$ aspiration catheter via $8 \mathrm{~F}$ long sheath or $5 \mathrm{~F}$ aspiration catheter via a flexible $8 \mathrm{~F}$ BGC. Thrombectomy was performed under direct visual control. The primary endpoints were the number of passes and the number of distal emboli.

Results Ten experiments were made with each clot model and thrombectomy technique $(n=40)$. Full recanalization could be achieved in every experiment. First pass $\mathrm{mTICI} 3$ could be achieved by 6 F ADAPT in $80 \%$ of red clots and $90 \%$ of white clots. Distal emboli were caused in $10 \%$ and $20 \%$, respectively. When using $5 \mathrm{~F}$ ADAPT combined with BGC, a first pass $\mathrm{mTICI} 3$ rate of $90 \%$ in red clots and $100 \%$ in white clots could be achieved. A $10 \%$ rate of distal emboli occurred in both groups. In almost all experiments (both techniques), the thrombi clogged the aspiration catheter. No statistically significant differences could be found between the techniques and clot models.

Conclusion 6F ADAPT without BGC was as effective as 5F ADAPT combined with a flexible 8F BGC, with both techniques showing high first-pass recanalization rates and low distal emboli rates. Especially in the case of a tortuous anatomy, these setups should be considered as alternatives to a rigid $9 \mathrm{~F} \mathrm{BGC}$. The thrombus compositions seemed to be irrelevant in this setting.

\section{Key Points:}

- 6F ADAPT with no BGC and 5F ADAPT with BGC were very effective and performed equally.

- Both techniques should be considered in tortuous anatomy.

- In this setting the clot composition showed no effect on the recanalization rate.

\section{Citation Format}

- Madjidyar J, Nerkada L, Larsen $\mathrm{N}$ et al. Choosing an Effective and Safe Direct Aspiration Setup for Tortuous Anatomy in Acute Ischemic Stroke: In vitro Study in a Physiological Flow Model. Fortschr Röntgenstr 2021; 193: 544-550

\section{Purpose}

Stent retriever thrombectomy represents the standard therapy of intracranial large vessel occlusions in addition to systemic lysis in acute ischemic stroke [1-5]. Special intermediate catheters have shown promising results in ADAPT (a direct aspiration, first-pass technique) [6, 7]. Balloon guide catheters (BGC) combined with stent retriever seem to provide better results than stent-retriever alone [8]. For large vessel occlusions different sizes of aspiration catheters are available. The largest aspiration catheters available (6F) seem to be more effective, but only fit in relatively rigid 9F BGCs (e.g. Merci BGC, Stryker, USA), which can result in more difficult and prolonged navigation or in complications such as cervical artery dissection. BGCs with higher distal flexibility (e. g. FlowGate 8F, Stryker, USA) are only suitable for the 5F aspiration catheters. In 2017 Stampfl et al. combined 5F ADAPT and BGC in their case series with favorable results [9], but they did not compare their results to an ADAPT only control group.

The matter of aspiration catheter sizing and the combination with a BGC can be addressed using different clot compositions and visualizing the interaction between the device and the clot in a flow model under standard conditions. The purpose of this study was to compare the efficacy of 6F ADAPT alone and 5F ADAPT combined with a reasonably flexible BGC.

\section{Materials and Methods}

\section{Flow model [10]}

The experiments were performed under standardized and physiological hemodynamic conditions. The flow model is made of transparent silicon (Elastrat, Switzerland) and is derived from patient data. The following parts of the model have physiological curvature and inner diameters: common carotid artery $(8 \mathrm{~mm})$, internal carotid artery $(6 \mathrm{~mm})$, proximal external carotid artery (5 mm), M1 segment (3 mm), proximal M2 segment (2.5 mm), A1 segment $(2.5 \mathrm{~mm})$. To decrease friction, the inside of the phantom was coated with a propranolol-based fluid (Elastrat Sarl, Switzerland) before each use. Glycerol solution was used to mimic blood $\left(60 / 40\right.$ by volume saline/glycerin; $\left.37^{\circ} \mathrm{C}\right)$. A precise, programmable piston pump (CompuFlow 1000, Shelley Medical Imaging Technologies, Canada) produced physiological fluid dynamics, which were monitored by Doppler sonography (carotid profile, velocity of $100 \mathrm{~cm} / \mathrm{s}$, pulse $60 / \mathrm{min}$ ). A mean pressure of $100 \mathrm{mmHg}$ was maintained. The clots were injected into the model and flowed into the M1 segment of the MCA. All thrombectomy procedures were video recorded (Panasonic HC-V250, Japan; Full High Definition, $60 \mathrm{fps}$ ). Simultaneously, the video signal was broadcast to a monitor simulating an angio suite-like setup ( $\vdash$ Fig. 1) [10]. 


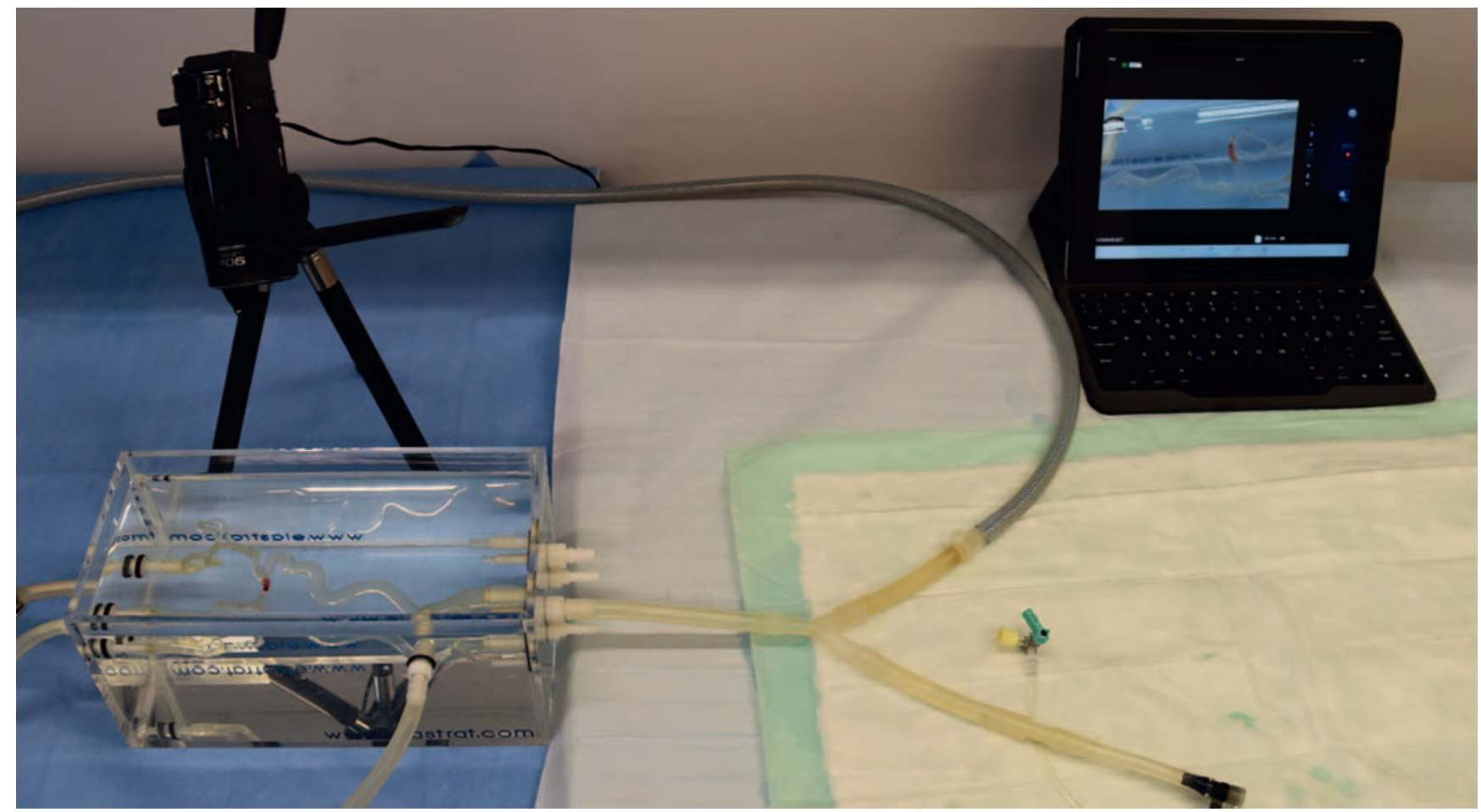

- Fig. 1 Angio suite-like experimental setup showing silicon phantom, camera, and monitor.

- Abb.1 Angiografie-ähnlicher Versuchsaufbau mit Silikonmodell, Kamera und Monitor.

\section{Clot models [10]}

Two different clot models were used for the experimental studies [10-13]:

1. An erythrocyte-rich (red) clot: fresh human blood was put in a Chandler loop system to create a thrombus under dynamic conditions. The clots were cut into pieces of $10 \times 3.5 \mathrm{~mm}$ in size.

2. A fibrin-rich (white) clot: citrated human blood was stored standing for $24 \mathrm{~h}$. The plasma, the buffy coat, and a few erythrocytes were aspirated. The sample was recalcified and incubated for further $72 \mathrm{~h}$. The clots were cut into pieces of $10 \times 3.5 \mathrm{~mm}$ in size.

\section{ADAPT Techniques}

Two different recanalization techniques were used:

1. GF ADAPT alone: A 6F intermediate aspiration catheter (SOFIA 6F, Microvention, USA: inner diameter 0.070 in $(1.78 \mathrm{~mm})$, outer diameter $0.0815-0.0825$ in $(2.07-2.1 \mathrm{~mm})$, length $125 \mathrm{~cm}$,) was placed directly proximal to the occlusion site and continuous machine aspiration was performed (Penumbra Aspiration Pump, USA). If the tip was blocked by the clot, the intermediate catheter was pulled back into the long sheath (Neuron MAX 88, Penumbra, USA: inner diameter 0.088 in (2.24 mm), outer diameter 0.100 in $(2.54 \mathrm{~mm})$, length $90 \mathrm{~cm}$ ) in the ICA. While withdrawing the distal catheter, additional aspiration via the sheath was performed using a $20-\mathrm{ml}$ Luer-Lock syringe. If necessary, subsequent passes followed.
2. 5F ADAPT and BGC: $A 5 F$ intermediate aspiration catheter (SOFIA 5F, Microvention, USA: inner diameter 0.055 in (1.4 mm), outer diameter 0.067-0.068 in (1.7-1.73 mm), length $125 \mathrm{~cm}$ ) was placed directly proximal to the occlusion site and continuous machine aspiration was performed (Penumbra Aspiration Pump, USA). If the tip was blocked by the clot, the intermediate catheter was pulled back into the BGC (FlowGate2 8F, Stryker, USA: inner diameter 0.084 in $(2.13 \mathrm{~mm})$, outer diameter 0.106 in $(2.7 \mathrm{~mm})$, length $95 \mathrm{~cm})$ in the ICA. Just before the ADAPT maneuver the balloon of the BGC was inflated, creating a complete proximal flow arrest. Simultaneously, proximal manual aspiration was performed (20 ml Luer-Lock syringe) just before the intermediate catheter was retracted into the BGC. After the intermediate catheter was pulled out of the BGC, the balloon was deflated. If necessary, subsequent passes followed.

\section{Analysis and statistics}

The number of passes and the occurrence of distal emboli and emboli in new territories were documented. Distal emboli and emboli in the anterior cerebral artery were counted on the videos and in a filter system interposed between the phantom and the pump. The videos of the thrombectomy procedures were analyzed after the experiments.

Chi-squared test, Kruskal-Wallis test, and Mann-Whitney U test were performed. Given multiple comparisons, the Bonferroni correction was used. Statistical significance was set to $p<0.05$. 
- Table 1 Summary of the results.

- Tab. 1 Zusammenfassung der Ergebnisse.

\begin{tabular}{|c|c|c|c|c|c|}
\hline clot model & technique & $\begin{array}{l}\text { median number } \\
\text { of passes }\end{array}$ & $\begin{array}{l}\text { first pass full } \\
\text { recanalization }\end{array}$ & $\begin{array}{l}\text { rate of distal } \\
\text { emboli }\end{array}$ & $\begin{array}{l}\text { total number of } \\
\text { distal emboli }\end{array}$ \\
\hline \multirow[t]{2}{*}{ red (erythrocyte-rich) } & $5 F$ ADAPT + BGC & 1 & $90 \%$ & $10 \%$ & 1 \\
\hline & 6F ADAPT & 1 & $80 \%$ & $10 \%$ & 2 \\
\hline \multirow[t]{2}{*}{ white (fibrin-rich) } & $5 F$ ADAPT + BGC & 1 & $100 \%$ & $10 \%$ & 2 \\
\hline & 6F ADAPT & 1 & $90 \%$ & $20 \%$ & 4 \\
\hline
\end{tabular}

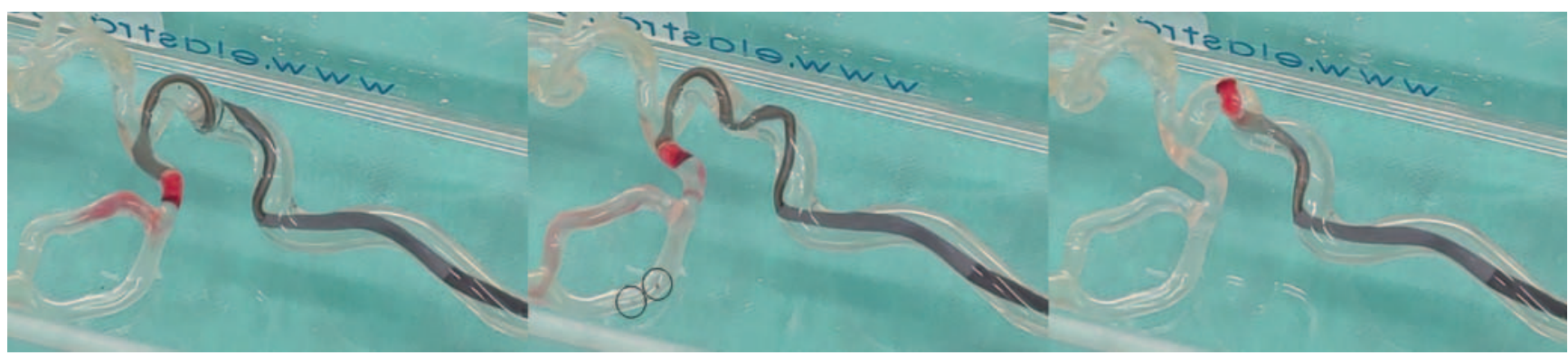

- Fig. 2 White thrombus retrieved by $6 \mathrm{~F}$ aspiration catheter and long sheath. The aspiration catheter was clogged by the thrombus and had to be retracted into the long sheath. Two distal emboli occurred (black circles in the middle picture).

- Abb.2 Weißer Thrombus geborgen mittels 6F-Aspirationskatheter und langer Schleuse. Der Aspirationskatheter wurde durch den Thrombus verstopft und musste in die lange Schleuse zurückgezogen werden. Zwei distale Embolien traten auf (schwarze Kreise).

\section{Results}

Ten experiments were conducted per thrombus model and thrombectomy technique, resulting in a total of $n=40$ experiments. > Table 1 shows a summary of the results. > Fig. 2-4 show aspects of the clot retrieval (consecutive frames from the videos of the experiments).

\section{F ADAPT alone}

Both in white and in red clots a median of one pass was needed for full recanalization (max. 2 passes). A first-pass mTICI 3 (modified treatment in cerebral infarction score) rate of $80 \%$ was achieved in red clots and $90 \%$ in white clots. The catheter was clogged by the thrombus in $90 \%$ of the experiments, though the thrombus had to be pulled back into the sheath unprotected ( $\vee$ Fig. 2). A total of six distal emboli in three experiments occurred (in one red clot and two white clots, $>$ Fig. 2), resulting in an embolization rate of $10 \%$ in red clots and $20 \%$ in white clots. The size of the emboli was $<1 \mathrm{~mm}$. No emboli in new territories occurred.

\section{F ADAPT and BGC}

As in the 6F ADAPT group, a median of one pass provided full recanalization (max. 2 passes). However, the first-pass $\mathrm{mTICl} 3$ rate was higher than in the 6F ADAPT group with $90 \%$ in red clots and
$100 \%$ in white clots. The $5 \mathrm{~F}$ catheter was clogged by the thrombus in all but one case ( $\bullet$ Fig. 3 ), with loosening in the ICA in one case, but the flow reversal via the BGC did prevent another pass ( $\vdash$ Fig. 4). Moreover, less distal emboli occurred: three emboli in two experiments (in one red and one white thrombus), with a total emboli rate of $10 \%$ per clot model. The size of the emboli was $<1 \mathrm{~mm}$. No emboli in new territories occurred.

The results showed no statistically significant differences between the thrombectomy techniques and clot models.

\section{Discussion}

6F ADAPT alone and 5F ADAPT combined with an 8F BGC were highly effective in retrieving both red and white clots in this experimental setting. The overall rate of distal emboli was low in both groups. In red clots more distal emboli occurred, but the difference was marginal. There were some slightly better first-pass recanalization rates and lower distal emboli rates with 5F ADAPT and BGC. Due to the lack of collateral flow in this model (missing anterior communicating artery and posterior communicating artery), the flow reversal might be more powerful than it would be in vivo. None of the results were statistically significant.

Stampfl et al. [9] showed in their case series that BGC combined with ADAPT using SOFIA 5F and Cello 8F (Medtronic, USA) 


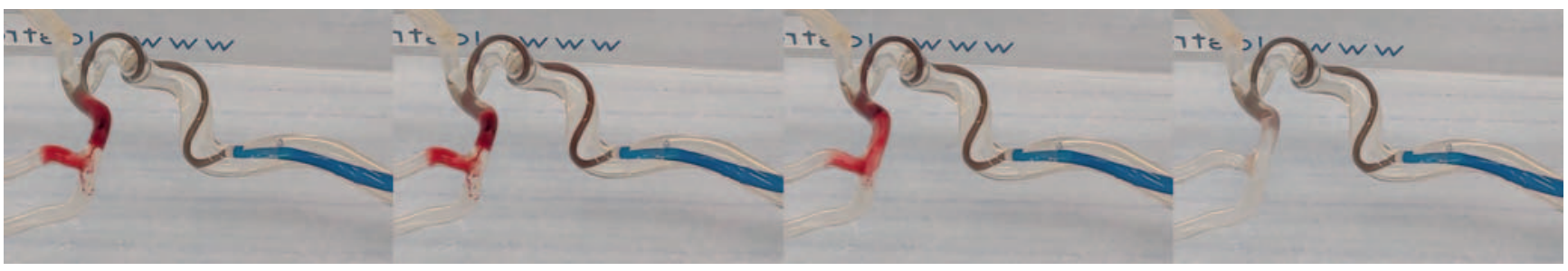

- Fig. 3 Red thrombus retrieved by $5 \mathrm{~F}$ aspiration catheter and balloon guide catheter. The thrombus is aspirated directly at the occlusion site. No distal emboli occurred.

- Abb.3 Roter Thrombus geborgen mittels 5F-Aspirationskatheter und Ballon-Führungskatheter. Der Thrombus wird direkt an der Verschlussstelle aspiriert. Es sind keine distalen Embolien aufgetreten.

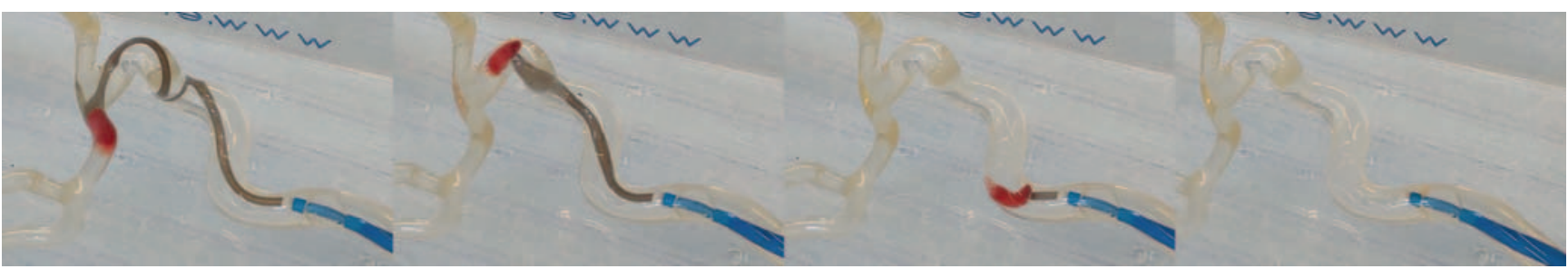

- Fig. 4 White thrombus retrieved by 5F aspiration catheter and balloon guide catheter (BGC). The aspiration catheter is clogged and was pulled back into the BGC. Final retrieval was achieved by aspiration via BGC. No distal emboli occurred.

- Abb.4 Weißer Thrombus geborgen mittels 5F-Aspirationskatheter und Ballon-Führungskatheter (BGC). Der Aspirationskatheter wurde durch den Thrombus verstopft und wurde in den BGC zurückgezogen. Die letztliche Rekanalisation wurde durch den BGC gewährleistet.

is feasible and safe in a clinical setting, as well. Since 2017, larger $6 \mathrm{~F}$ aspiration catheters are available, those fit only into rather rigid 9F BGCs (e. g. Mercy, Stryker; Cello, Medtronic). We did not choose the largest available BGC because of the anatomy anticipated in an average patient with acute ischemic stroke: A tortuous anatomy is rather common than a rarity [14]. A rigid system like the Mercy 9F BGC has been shown to be very challenging to place [8] and could result in a relevantly longer procedure time. It might be more traumatic, too, potentially causing dissection or severe vasospasm, and the need of further interventional or surgical procedures [15]. From our point of view the FlowGate 8F BGC is a good compromise: It is more flexible distally than any BGC available and allows placement of a $5 \mathrm{~F}$ aspiration catheter. Clinical trials showed superiority of stent retrievers combined with BGC compared to thrombectomies without BGC concerning angiographical results and clinical outcome $[16,17]$. Other clinical trials showed that ADAPT (e. g. with SOFIA or ACE) is a highly effective thrombectomy technique, with an even faster procedure time and a non-inferior clinical outcome compared with the outcome of the randomized stent retriever trials [18-20]. The ASTER Study [21] compared ADAPT with no BGC and SR combined with BGC: The results were not significantly different. Given its superiority design to detect a $15 \%$ difference in the primary end point, this trial was not designed to establish non-inferiority between contact aspiration and stent retriever as first-line endovascular strategies and was not designed to detect a smaller yet potentially clinically important difference between groups. In vitro studies showed similar results [10]. In 2019 Turk et al. showed the noninferiority of aspiration thrombectomy as a first-line approach compared with stent retriever in a randomized, blinded outcome, multi-centric study (COMPASS) [22]. Also in 2019, the American Heart Association and American Stroke Association updated the 2018 Guidelines for the Early Management of Acute Ischemic Stroke: Direct aspiration is equal to stent retriever for mechanical thrombectomy - class I (strong) recommendation [23]. A clinical study by Kang et al. concluded that BGC significantly increased the final and first-pass recanalization rates of ADAPT [24]. However, this study has a major drawback: Very heterogeneous devices were used, mainly distal access catheters not especially designed for ADAPT. The inner diameter of those catheters was not mentioned. That might be the reason for the relatively low firstpass recanalization rate of $19 \%$ without BGC and $47 \%$ combined with BGC. A study from 2019 showed that larger aspiration catheters increase the first-pass efficacy of the ADAPT technique [25]. No BGC was used and the first-pass recanalization rate was $53 \%$.

Although stent retriever thrombectomy combined with BGC is currently favored by many groups, direct aspiration is at least a complementary alternative. Proximal thrombi that are difficult to pass through with a microcatheter can be easily addressed with a sufficient aspiration catheter. Long thrombotic occlusions of the distal ICA, in which several passes are necessary, can be aspirated faster, because a pass does not take as much time as a stent retriever pass would. Further, thrombi which "ride" on an MCA bifurcation might be more suited for ADAPT than for a stent retriever (e. g. kissing or dual stent retriever technique [26]).

Using stent retrievers it has been discussed, if clot composition has an influence on recanalization success. For the moment the clot attenuation on non-enhanced CT is promising in predicting 
clot composition: There is a link between the density of the clot and the histological composition. Erythrocyte-rich thrombi are more hyperdense than fibrin-rich thrombi [27, 28]. However, to date, there are no methods available that could predict thrombus composition reliably. In our study we used two extreme thrombi and achieved not significantly different results.

In comparison to clinical studies, the transparent design of our silicon phantom showed that both aspiration via the long sheath and the BGC made the procedure more safe, because proximally fragmented parts of the clot could be aspirated. The in vitro design of this study leads to some limitations. Many physiological aspects like the lack of endothelium, coagulation factors, and blood cells apart from the thrombus were not established in this experimental setting. Furthermore, the collateral flow is missing. Overall, it is an artificial environment, which should always be considered when interpreting the results of this study. A clinical outcome cannot be predicted, but a low rate of distal emboli and a high first-pass recanalization rate were presumed to be positive factors for favorable outcome.

\section{Conclusion}

6F ADAPT without BGC was as effective as 5F ADAPT combined with a flexible $8 \mathrm{~F}$ BGC, with both techniques showing high firstpass recanalization rates and low distal emboli rates. 5F ADAPT with BGC showed slightly better, but statistically not significant results. In the case of a tortuous anatomy, these setups should be considered as an alternative to rigid $9 F$ BGC combinations to prevent prolonged delivery and complications. In a straight anatomy, 6F ADAPT combined with 9F BGC would probably be the better choice. In this setting the thrombus composition had no effect on the recanalization success, but it surely does in the clinical setting. Clinical studies are necessary to validate these data.

\section{CLINICAL RELEVANCE}

- 6F ADAPT alone or 5F ADAPT in combination with a flexible $8 \mathrm{~F}$ BGC should be considered in large vessel occlusion in the case of a tortuous anatomy.

- Both techniques were very effective with no statistically significant differences.

- The clot composition seemed to have no effect on the recanalization results in this setting.

\section{Conflict of Interest}

Fritz Wodarg declares that he has worked as a consultant for Microvention within the past 3 years and has received lecture fees from Microvention.

\section{References}

[1] Berkhemer OA, Fransen PS, Beumer D et al. A randomized trial of intraarterial treatment for acute ischemic stroke. N Engl J Med 2015; 372: $11-20$
[2] Saver LL, Goyal M, Bonafe A et al. Stent-retriever thrombectomy after intravenous t-PA vs. t-PA alone in stroke. N Engl J Med 2015; 372: 22852295

[3] Goyal M, Demchuk AM, Menon BK et al. Randomized assessment of rapid endovascular treatment of ischemic stroke. N Engl J Med 2015; 372: 1019-1030

[4] Jovin TG, Chamorro A, Cobo E et al. Thrombectomy within 8 hours after symptom onset in ischemic stroke. N Engl J Med 2015; 372: 2296-2306

[5] Campbell BC, Mitchell PJ, Kleinig T] et al. Endovascular therapy for ischemic stroke with perfusion-imaging selection. N Engl J Med 2015; 372 : 1009-1018

[6] Stampfl S, Kabbasch C, Müller M et al. Initial experience with a new distal intermediate and aspiration catheter in the treatment of acute ischemic stroke: clinical safety and efficacy. J Neurointerv Surg 2016; 8: 714-718

[7] Turk AS, Frei D, Fiorella D et al. ADAPT FAST study: a direct aspiration first pass technique for acute stroke thrombectomy. J Neurointerv Surg 2014; 6: 260-264

[8] Zaidat OO, Mueller-Kronast NH, Hassan AE et al. Impact of Balloon Guide Catheter Use on Clinical and Angiographic Outcomes in the STRATIS Stroke Thrombectomy Registry. Stroke 2019; 50 (3): 697-704

[9] Stampfl S, Pfaff ], Herweh C et al. Combined proximal balloon occlusion and distal aspiration: a new approach to prevent distal embolization during neurothrombectomy. J Neurointerv Surg 2017; 9: 346-351

[10] Madjidyar J, Hermes J, Freitag-Wolf S et al. Stent-thrombus interaction and the influence of aspiration on mechanical thrombectomy: evaluation of different stent retrievers in a circulation model. Neuroradiology 2015; 57: 791-797

[11] Liebeskind DS, Sanossian N, Yong W et al. CT and MRI early vessel signs reflect clot composition in acute stroke. Stroke 2011; 42: 1237-1243

[12] Chandler AB. In vitro thrombotic coagulation of the blood; a method for producing a thrombus. Lab Invest 2014; 7: 110-114

[13] Duffy S, Farrell M, McArdle K et al. Novel methodology to replicate clot analogs with diverse composition in acute ischemic stroke. J Neurointerv Surg 2017; 9 (5): 486-491

[14] Dumont TM, Bina RW. Difficult Vascular Access Anatomy Associated with Decreased Success of Revascularization in Emergent Thrombectomy. J Vasc Interv Neurol 2018; 10 (2): 11-14

[15] Jeong DE, Kim JW, Kim BM et al. Impact of Balloon-Guiding Catheter Location on Recanalization in Patients with Acute Stroke Treated by Mechanical Thrombectomy. AJNR Am J Neuroradiol 2019; 40 (5): 840-844

[16] Brinjikji W, Starke RM, Murad MH et al. Impact of balloon guide catheter on technical and clinical outcomes: a systematic review and metaanalysis. J Neurointerv Surg 2018; 10: 335-339

[17] Teleb MS. Endovascular Acute Ischemic Stroke Treatment with FlowGate Balloon Guide Catheter: A Single-Center Observational Study of FlowGate Balloon Guide Catheter Use. Interv Neurol 2018; 7 (6): 327-333

[18] Maegerlein C, Prothmann S, Lucia KE et al. Intraprocedural Thrombus Fragmentation During Interventional Stroke Treatment: A Comparison of Direct Thrombus Aspiration and Stent Retriever Thrombectomy. Cardiovasc Intervent Radiol 2017; 40 (7): 987-993

[19] Turk AS, Turner R, Spiotta A et al. Comparison of endovascular treatment approaches for acute ischemic stroke: cost effectiveness, technical success, and clinical outcomes. J Neurointerv Surg 2015; 7 (9): 666-670

[20] Schramm P, Navia P, Papa R et al. ADAPT technique with ACE68 and ACE64 reperfusion catheters in ischemic stroke treatment: results from the PROMISE study. J Neurointerv Surg 2019; 11 (3): 226-231

[21] Lapergue B, Blanc R, Gory B et al. Effect of Endovascular Contact Aspiration vs Stent Retriever on Revascularization in Patients With Acute Ischemic Stroke and Large Vessel Occlusion: The ASTER Randomized Clinical Trial. JAMA 2017; 318 (5): 443-452 
[22] Powers W], Rabinstein A, Ackerson T et al. Guidelines for the Early Management of Patients With Acute Ischemic Stroke: 2019 Update to the 2018 Guidelines for the Early Management of Acute Ischemic Stroke: A Guideline for Healthcare Professionals From the American Heart Association/American Stroke Association. Stroke 2019; 50 (12): e344e418

[23] Turk AS, Siddiqui A, Fifi JT et al. Aspiration thrombectomy versus stent retriever thrombectomy as first-line approach for large vessel occlusion (COMPASS): a multicentre, randomised, open label, blinded outcome, non-inferiority trial. Lancet 2019; 393: 998-1008

[24] Kang DH, Kim BM, Heo JH et al. Effect of balloon guide catheter utilization on contact aspiration thrombectomy. J Neurosurg 2018; 1: 1-7
[25] Delgado Almandoz JE, Kayan Y, Wallace AN et al. Larger ACE 68 aspiration catheter increases first-pass efficacy of ADAPT technique. J Neurointerv Surg 2019; 11 (2): 141-146

[26] Patro SN, lancu D. Dual-stent retrieval for mechanical thrombectomy of refractory clot in acute stroke as a rescue technique. CMAJ 2017; 189 (17): E634-E637

[27] Sporns PB, Hanning U, Schwindt W et al. Ischemic Stroke: Histological Thrombus Composition and Pre-Interventional CT Attenuation Are Associated with Intervention Time and Rate of Secondary Embolism. Cerebrovasc Dis 2017; 44 (5): 344-350

[28] Borggrefe J, Kottlors ], Mirza M et al. Differentiation of Clot Composition Using Conventional and Dual-Energy Computed Tomography. Clin Neuroradiol 2018; 8 (4): 515-522 